\title{
MEDIAÇÃO DA INFORMAÇÃO E A ORGANIZAÇÃO DO CONHECIMENTO: INTERRELAÇÕES
}

\section{MEDIACIÓN DE LA INFORMACIÓN Y LA ORGANIZACIÓN DEL CONOCIMIENTO: INTERRELACIONES}

\author{
Oswaldo Francisco de Almeida Júnior - ofaj@ofaj.com.br \\ Doutor em Ciências da Comunicação pela Universidade de São Paulo \\ (USP). Professor do Programa de Pós-Graduação em Ciência da \\ Informação da Universidade Estadual Paulista (UNESP/Marília).
}

João Arlindo dos Santos Neto - santosneto@uel.br Mestre em Ciência da Informação da Universidade Estadual Paulista (UNESP/Marília). Professor do Departamento de Ciência da Informação da Universidade Estadual de Londrina (UEL).

\section{RESUMO}

Introdução: Este artigo apresenta conceitos e definições dos termos mediação da informação e organização do conhecimento, a partir de um referencial teórico.

Objetivo: Apresentar o processo de mediação da informação no processo de organização do conhecimento, na percepção dos alunos do curso de Biblioteconomia e dos bibliotecários.

Metodologia: Foi aplicado um questionário aos alunos e aos bibliotecários, para confrontar a literatura com os dados obtidos, utilizou-se como metodologia a análise de conteúdo.

Resultados: Apresenta como resultados a maneira que os alunos e bibliotecários percebem os temas discutidos.

Conclusões: Conclui-se que a mediação da informação além de ser uma interferência, determina todo fazer do bibliotecário; que esta ainda não está clara para maioria dos respondentes; e que as ações da organização do conhecimento aparecem também como ações de mediação no fazer diário dos profissionais da informação. 
Palavras-chaves: Mediação da informação. Interferência. Organização do conhecimento. Organização da Informação. Biblioteca Universitária.

\section{INTRODUÇÃO}

A organização do conhecimento e da informação sempre acompanhou as pessoas e as organizações. Nas unidades de informação e nas empresas a preocupação é com o acesso às informações. Para que haja o acesso, é necessário que as informações e os documentos sejam organizados e tratados da melhor maneira. Atualmente, se vê o aumento na formação de novas áreas do conhecimento e na produção de informação devido ao crescimento e avanço das pesquisas nas mais diversas disciplinas e campos de atuação. A busca por novas perspectivas faz com que os pesquisadores e cientistas utilizem e apliquem técnicas e métodos de pesquisa fora do contexto disciplinar original, ou seja, a interdisciplinaridade contribui para a solução de problemas específicos.

Esse artigo teve como interesse analisar inicialmente os aspectos da Biblioteconomia e Ciência da Informação $(\mathrm{Cl})$, direcionados para a mediação da informação e a organização do conhecimento. A mediação da informação está presente em todas as atividades do profissional da informação, serviço de referência, atividades culturais, contação de histórias, e, inclusive no processamento técnico, ou seja, classificação e catalogação, que fazem parte da organização do conhecimento. Sendo assim, é necessária a utilização de ferramentas de apoio na execução desta tarefa, como exemplos bem próximos têm-se a Classificação Decimal Universal, Classificação Decimal de Dewey e as tabelas Pha e Cutter. O processo de mediação aparece também nessa etapa tão relevante nas bibliotecas, 0 de organizar o conhecimento e a informação, em que o bibliotecário prepara fisicamente uma possível informação para disponibilizá-la para os usuários/leitores.

O objetivo principal foi analisar a percepção dos alunos do curso de Biblioteconomia, que cursaram a disciplina Mediação da Informação no ano de 2010, e dos(as) Bibliotecários(as) da Biblioteca Central da Universidade Estadual de Londrina quanto à mediação da informação no processo de organização do conhecimento.

Sabendo-se que a mediação da informação é indispensável no serviço do bibliotecário, a pesquisa buscou conhecer com os discentes e profissionais da 
instituição, como eles têm construído conhecimento a respeito desse tema. O questionamento propõe auscultar as pessoas que atuam na área, como também os alunos que estudam Biblioteconomia, visando descobrir como eles entendem a mediação da informação no processo de organização do conhecimento.

Ao decorrer deste artigo, apresentar-se-á conceituações e definições dos termos: mediação da informação, organização do conhecimento e organização da informação. A leitura crítica e interpretativa dos questionários e, posteriormente, a análise de conteúdo, foram os principais procedimentos adotados na metodologia. A classificação das categorias entre as respostas foi elaborada por meio da identificação de características e proximidade nas respostas obtidas em casa questão. Pelos resultados obtidos, foi possível constatar que diferentes formas de entendimento e compreensão são encontradas a respeito da mediação e da organização do conhecimento.

\section{Mediação da Informação}

Ouve-se muito falar em mediação, mas não é sempre feita uma análise ou reflexão sobre seu sentido, sua definição, usabilidade e relevância. Na maioria das vezes pensa-se mediação no sentido de ponte, ou ainda mais especificamente, como objeto estático, concreto, onde este objeto fizesse papel apenas de "transmitir de um lado para o outro" uma mensagem/informação. Acredita-se, porém, que mediação é mais que somente uma "ponte transmissora".

Ao buscar o significado de mediação em Luft (2000, p. 449), deparou-se com a seguinte definição "ato ou efeito de mediar" ou com os termos "intercessão, intervenção". Sendo assim, justifica-se mais ainda a ideia de que a mediação deixa de ser um termo que descreve algo somente "concreto" e passa a ser um ato à ser realizado.

A mediação só ocorre quando há interferência de alguém, este que interfere é denominado como mediador. É simples entendermos como um mediador pode facilitar muitas conversas e acordos, mesmo que sem desconsiderá-la ou manipulála. Da mesma forma que o termo mediação é utilizado e empregado em diversas áreas do conhecimento, o mediador também está presente nelas. $O$ mediador no pensamento de Bicheri (2008) "pode ser um professor, um padre, um pastor, um escritor, um jornalista, um apresentador de televisão ou rádio, um bibliotecário, um 
crítico de cinema, entre outros". Cada mediador tem sua devida importância e um papel à ser desempenhado na sociedade.

No entanto o foco deste artigo é abordar a mediação dentro da Biblioteconomia e Ciência da Informação, e neste caso a mediação da informação. O mediador, no âmbito da área aqui analisada, passa a ser o bibliotecário. É fundamental que o mediador bibliotecário e suas características sejam exploradas em toda a sua potencialidade, é necessário que este profissional acredite e internalize o seu papel transformador em todos os ambientes dentro de uma biblioteca/instituição.

O termo mediação da informação tem sido utilizado na Ciência da Informação, mas ainda não foi aceito conceitualmente. No entanto, Davallon (2007, p. 3) afirma que, "algumas destas utilizações estão, com toda a evidência, bastante distantes de uma qualquer reflexão sobre o estatuto científico do termo", ou seja, o termo é utilizado sem conhecimento.

Sanches e Rio (2010, p. 104) afirmam que "a interação do bibliotecário com o usuário no processo de aquisição da informação" é fundamental, e ainda que "o processo de mediação da informação se constitui pela interação informação/bibliotecário/usuário". No entanto, acredita-se que a mediação vai além da interação com o usuário.

Segundo Almeida Júnior (2009, p. 92), o conceito de mediação da informação é

Toda interferência - realizada pelo profissional da informação -, direta ou indireta; consciente ou inconsciente; singular ou plural; individual ou coletiva; que propicia a apropriação de informação que satisfaça, plena ou parcialmente, uma necessidade informacional.

A mediação da informação não é passiva, é uma ação de interferência, acompanha todo o fazer do bibliotecário, ainda que indireta e inconscientemente. Ela não é neutra, não pode ser imparcial, o bibliotecário deve assumir seu papel e não simplesmente esperar que os usuários busquem a informação somente ao se depararem com uma necessidade informacional.

Entende-se que mediação da informação está diretamente ligada às ações implícitas e explícitas, voltadas para o usuário, e que a mesma é fundamental nas práticas do profissional da informação. $O$ caráter da mediação depende não 
somente das ações realizadas pelos bibliotecários, como também da presença imediata/física ou não dos usuários.

Almeida Júnior (2007a, p. 34) afirma que

Há que se ficar bem claro, também, que na mediação existe "interferência" do profissional que atua no espaço em que ela é deflagrada. A interferência contradiz o senso comum dos profissionais da área que defende uma impossível neutralidade no âmbito do fazer desses profissionais. Não só a interferência é salutar, como é, também imprescindível. Os limites entre a interferência e a manipulação, no entanto, são frágeis e passíveis de não serem percebidos.

A interferência (explícita ou implícita) realizada pelo profissional da informação é fundamental em todos os serviços e produtos oferecidos em unidades informacionais. Ainda que exista a relutância em acreditar nessa interferência os profissionais da área de Ciência da Informação esperam que os usuários compreendam que essa interferência ocorre com objetivo de colaboração e não de manipulação. Essa ideia de interferência, segundo Bortolin (2010), fica mais clara ao afirmar que a mediação da informação, além de indispensável, é uma ação presente nas atividades cotidianas de uma biblioteca; "que o leitor age ativamente no momento de se apropriar da informação e que o profissional envolvido na mediação da informação não é neutro, pois recebe influência do leitor e o influencia também".

Para Almeida Júnior (2004b, p. 86),

[...] mais do que a informação, o bibliotecário deve estar preocupado com a mediação dessa informação. Hoje, nossa reflexão aponta para a mediação - muito mais do que a informação - como o objeto principal da biblioteconomia e, portanto, do fazer do bibliotecário. Tendo a mediação como diretriz, como norte, como objeto, o bibliotecário pode alterar, pode transformar sua ação social, não a ideal, mas a real.

Apoiando-se na citação acima é evidente que o profissional da informação deve se preocupar com a mediação da informação e não somente com a "informação". Com isso, o bibliotecário poderá exercer seu papel profissional e social como demanda à realidade e não como um fazer idealizado. O que se observa é uma dissonância entre o ideal e o real, pois muitas vezes os bibliotecários buscam uma "suposta" neutralidade que é fruto de uma atuação focalizada ainda nos suportes de informação, e não no acesso e/ou mediação. 
O fazer do bibliotecário ainda não é tão valorizado quanto gostaríamos, talvez porque seu serviço não é visto como um fazer, um ato que resulte em mudanças e/ou transformações sociais, mas sim como apoio quase não requisitado. Para explicar a situação referida, Almeida Júnior (2002, p.141) diz que "a culpa da formação na existência de concepções desse tipo nos egressos das universidades, embora não única, é inquestionável".

Segundo Dias (2000, p.68) "não é raro o interlocutor ficar surpreso ao saber que existe mestrado na área; doutorado, então, é motivo de enorme perplexidade". O autor ainda afirma que as pessoas possuem noção do que sejam as outras áreas de estudos como física, química, medicina, direito entre outras, porque estas "tocam" diretamente a vida das pessoas e que na área de Biblioteconomia e Ciência da Informação "a discussão pode servir como um instrumento básico para a institucionalização social da especialidade" (DIAS, 2000, p. 68).

Essa realidade talvez possa ser justificada pelo fato de que algumas pessoas não imaginam ou enxergam o profissional bibliotecário com titulação de mestre e/ou doutor atuando em organizações distintas, mas somente na academia e bibliotecas.

É explícito que a maioria dos estudantes que ingressam no curso de Biblioteconomia já possui uma imagem sobre o bibliotecário, no entanto, ao decorrer da graduação bem como na realização dos estágios, é possível vislumbrar campos diversos de atuação profissional como também uma variedade de subáreas para desenvolvimento de pesquisas nas área.

O objetivo das bibliotecas vai além do fornecimento da informação, mas buscando a apropriação dela pelo usuário. Ainda que esse serviço permaneça pouco valorizado. Defende-se que as atividades que são desempenhadas pelos bibliotecários devem ter como principal objetivo o acesso e a apropriação de informações, tornando a função do bibliotecário, efetivamente, uma mediação entre o usuário e a informação. Firma-se novamente que, através das atividades de organização e representação do conhecimento, como também na interação com os usuários (para que eles possam ultrapassar do ponto de sua "necessidade imediata", para gerar significações e atribuir valor e sentido aos conteúdos informacionais acessados), é que se concretiza, também, o processo de mediação.

No entanto, já que se trata de um serviço que é procurado pelo usuário, o fornecimento da informação "é dependente" da organização do conhecimento, 
motivo pelo qual os bibliotecários responsáveis pelas "ações internas" deveriam ter conhecimento do quanto suas atividades são importantes.

Devido às conceituações apresentadas sobre mediação da informação, é necessário que se elucide a importância da interferência em qualquer atividade do profissional da informação. Certamente deve-se buscar a imparcialidade quanto a essa interferência, mesmo sabendo que ela não será alcançada. Além disso, é necessário diferenciar interferência de manipulação. Ao se buscar o significado de interferência, de acordo com Luft (2000, p. 397) deparou-se com a expressão "ação ou efeito de interferir" e com os termos "intervenção, intromissão". A manipulação segundo Luft (2000, p.441) é definida no sentido de "manusear em vista dos próprios interesses; forjar; dominar". Buscar o equilíbrio entre essas duas áreas é imprescindível, mesmo que seja difícil.

A mediação pode ocorrer em qualquer espaço informacional e dentro desse espaço ela pode aparecer em cada "segmento que o constitui". As manifestações de mediação que são mais vistas nas bibliotecas são as ações realizadas pelo bibliotecário no Serviço de Referência e Informação. Vê-se aqui mais um motivo pelo qual deve existir a valorização e auto reconhecimento entre os profissionais da informação.

Segundo Almeida Júnior (2004a) a atuação do bibliotecário,

[...] como mediador da informação, não se realiza de maneira apática, passiva, amorfa, mas ao contrário, o resultado da mediação carrega uma interferência até mesmo objetiva do bibliotecário e que ocorre em todo o processo, em todas as instâncias e segmentos do fazer desse profissional.

Mesmo que a mediação seja mais facilmente percebida nos serviços finais das bibliotecas, ela está presente desde o momento de planejamento e da determinação das ações que ocorrerão na unidade de informação. Então a classificação e catalogação não devem ser exercidas unicamente como sendo técnicas neutras e imparciais, mas primordialmente como atividades voltadas para 0 usuário/leitor da unidade de informação.

Atualmente, mesmo com a evolução ininterrupta das tecnologias de informação e comunicação, o potencial do espaço físico "biblioteca" e do livro impresso, não faz firmar o pensamento do fim da profissão bibliotecária. Essa situação deve-se também a existência de novos suportes informacionais e não 
somente do texto escrito, como por exemplo os periódicos que já surgem no meio digital, os e-books, etc.

Deixa-se de lado a imagem existente do bibliotecário como aquele responsável pela guarda, preservação e organização da informação registrada somente nos livros e nos documentos impressos.

Almeida Júnior (2004a) afirma que, "a razão de ser do bibliotecário se encontra na mediação da informação".

No entanto, a mediação não pode ficar restrita apenas às atividades que são direcionadas diretamente ao usuário como dito acima, mas sim em todo fazer do bibliotecário, como visto anteriormente; a mediação se dá com ou sem a presença física do usuário. A mediação aparece de maneira implícita no momento da escolha dos materiais que farão parte do acervo da biblioteca, posteriormente no processamento técnico; já no Serviço de Referência e Informação a mediação aparece de maneira explícita. Sabendo que nas atividades de mediação explícita existe maior interação entre o bibliotecário e o usuário, na implícita/indireta é imprescindível também que haja uma preocupação e atenção do bibliotecário em se atentar às mudanças para melhoria e inovação no processo de comunicação com o usuário.

É uma tendência de muitos bibliotecários restringirem suas ações aos poucos gêneros de documentos, e este comportamento segundo Bortolin (2010) permite que "a sociedade atrele a sua imagem apenas às bibliotecas, pior do que isso leva a maioria dos profissionais da Biblioteconomia a avaliar que o objeto da Ciência da Informação é apenas a informação registrada".

Ao reconhecer a importância da mediação, Almeida Júnior (2006), enfatiza que na área o objeto de estudo deixa de ser a informação em si, e passa a ser a mediação dela. Visto a importância da mediação da informação no cotidiano do bibliotecário, o processo de organização do conhecimento é uma etapa em que ocorre a mediação.

\section{Organização do Conhecimento e da Informação}

Ao se tratar de organização do conhecimento, um dos nomes mais importantes que ganham destaque nos estudos teóricos da área, é o de Shiyali Ramamrita Ranganathan. Pioneiro na aplicação de fundamentos científicos na 
Biblioteconomia, ele continua colaborando para o entendimento da teoria e natureza do conhecimento, além de ser fonte da atividade classificatória do conhecimento. Ranganathan observa a organização do conhecimento e a classificação como sinônimos, assim como conhecimento e informação (NAVES, 2006, p. 40). Um dos precursores da classificação e organização do conhecimento, Ranganathan pensou os modos de relação possíveis que se aproximam e muito da representação do conhecimento. De acordo com Souza; Silva (2007) surgiu em 1963 na Colon Classification, os cinco tipos de relações de assuntos compostos: Relação Geral, Relação de Intenção, Relação de Comparação, Relação de Diferença e Relação de Influência.

Os termos organização do conhecimento e organização da informação são muito próximos, no entanto há características que os distinguem. Por exemplo, falase em organização da informação como se fosse um sinônimo de organização do conhecimento, quando isso não é verdade. Ou também fala-se em organização do conhecimento como processo que ocorre nas bibliotecas que visa construir representações de conhecimento, ou então como área de estudo, que é um campo interdisciplinar, que se atenta aos estudos da cognição humana, etc.

Para Cervantes (2009) "a organização da informação preocupa-se com a organização de um objeto físico, material" e "organização do conhecimento refere-se à organização da cognição humana".

Organizamos a informação todos os dias, seja no trabalho, em casa, na universidade, no telefone celular, no computador, etc. Realizamos esse processo, pois sem a informação organizada é muito difícil, ou até mesmo inviável, que consigamos desenvolver determinadas atividades, a dispersão da informação nos demanda tempo, nos deixa aflitos e desesperados. No entanto, essa organização é muito particular, na maioria das vezes apenas nós mesmos é que sabemos onde encontrar cada informação. Segundo Galvão (2008, p. 203), "esta limitação ocorre porque o modo de organização da informação adotado por nós não foi pensado para ser compreendido por todos aqueles que nos cercam, não sendo amplamente apreensível".

Sabendo que a sociedade necessita de informação, a organização e o compartilhamento desta são imprescindíveis para que haja o acesso à todas as pessoas. No contexto da organização da informação trabalha-se com os registros da informação, com objetos físicos e concretos, distantes das ideias e das cognições, 
ou seja, quando se trata de organização da informação delimita-se ao tratamento da informação registrada.

Bräscher e Café (2008, p. 5) afirmam que "o objetivo do processo de organização da informação é possibilitar o acesso ao conhecimento contido na informação". A organização da informação busca uma estruturação concreta, porém não estática, dos documentos e informação a partir dos processos de descrição física e de conteúdo. Para Gomes; Guimarães (2010) não menos importante que a produção e o consumo intensivo do conhecimento, é a sua organização e o seu tratamento a fim de torná-lo representável e recuperável igualmente em escala global.

Para que haja produção de conhecimento/informação e seu consumo, é necessário que anteriormente a informação esteja organizada e bem tratada.

De acordo com Souza (1998, p.7), "a organização do conhecimento tem sido uma das metas mais importantes da humanidade. Vem sendo realizada ao longo dos tempos, pois, através dela o homem espera tornar mais útil a apropriação e uso do saber produzido". Existem diversas formas de se organizar o conhecimento dependendo do objetivo específico. Quando se fala em organização há uma tendência a relacioná-la a uma mera ordem cronológica de documentos em uma simples ou complexa unidade de informação.

Seguindo o pensamento de Dahlberg apud Cervantes (2009), o objeto de estudo da organização do conhecimento é denominado como "conhecimento em ação", e que tenha sido registrado e socializado, para que a partir dele a sociedade possa se "apropriar" e então gerar mais conhecimento. A organização do conhecimento nunca deixou de estar presente nas atividades da Biblioteconomia e da recuperação da informação, no entanto as questões semânticas foram desconsideradas inicialmente com o surgimento das tecnologias e da informática.

Quando aborda-se a organização do conhecimento, trata-se dos conceitos e das ideias, e não mais das informações registradas. Ao contrário da organização da informação, a organização do conhecimento busca construir modelos de mundo que representam a realidade. A organização do conhecimento para Bräscher e Café (2008, p. 8) é delineada como "o processo de modelagem do conhecimento que visa a construção de representações do conhecimento". Neste processo, foca-se a análise dos conceitos e de suas características, para se estabelecer o local onde cada conceito ocupa dentro do esquema de representação, e como os demais 
conceitos existentes estão organizados na "cadeia" de conhecimento, ou nos mapas conceituais.

A Biblioteconomia tem os seus princípios científicos direcionados a organizar documentos e informação. Ela é pioneira na organização do conhecimento na sociedade. Não se deve esquecer, no entanto, que essa organização está voltada e se estrutura para a apropriação da informação por parte do usuário.

O fazer do bibliotecário abarca ações e atividades que, além da mediação da informação, incluem, como observado por Souza (1998, p. 9) "a organização prática do conhecimento para fornecimento de respostas aos usuários da informação e a organização e administração da coleção bibliográfica". Sendo assim, tornou-se indispensável ao profissional ter conhecimento de uma teoria que lhe forneça os critérios básicos para desempenhar as atividades referidas, com o propósito de tornar localizáveis os "pacotes de conhecimento". Entende-se Biblioteconomia como uma profissão e uma área do conhecimento que interfere no cotidiano de uma sociedade informacional, que a cada dia produz e publica mais informações em diferentes formatos de documentos. Atenta-se que por estar a organização, na maioria das vezes, atrelada à documentos formais e impressos, faz com que o bibliotecário se prenda basicamente a essas formas de documentos. Quando se delimita o fazer do profissional da informação a um trabalho com a coleção material em si, com objetivo de organizar esta coleção, mesmo sabendo que este fazer não é pouco, ainda se discute socialmente o resultado e reconhecimento da sua ação.

No âmbito da organização do conhecimento, antes da informação ser tratada, é necessário ter uma relação com ela, uma interação, uma apropriação com a leitura. Neste momento, não há neutralidade do bibliotecário, é preciso o uso da cognição deste profissional.

Enfatizando a importância não só da cognição humana, como também de demais fatores, Bufrem e Breda (2011, p. 189) afirmam que "o ambiente da organização do conhecimento está imbricado com espaços alternativos, descobertas e avanços tecnológicos, cujas fronteiras foram ampliadas na direção de temáticas como gestão do conhecimento e inteligência competitiva". As autoras supracitadas ressaltam que diante da dimensão em relação a organização do conhecimento, os profissionais da área se deparam com uma realidade na qual as tarefas estão em ritmo de expansão e de especificações mais precisas, e ainda que, termos como 
inteligência artificial e monitoramento tecnológico, entre outros, surgem "no sentido de facilitar a representação e utilização do conhecimento adquirido e organizado"

Atenta-se que as características do ambiente e de seus usuários são fatores determinantes no processo de organização do conhecimento.

\section{Metodologia}

A pesquisa tem caráter exploratório, descritivo, dentro de uma abordagem qualitativa, focando o processo de mediação da informação junto à organização do conhecimento, na percepção dos alunos de Biblioteconomia, que cursaram a disciplina Mediação da Informação no ano de 2010, e dos bibliotecários da Biblioteca Central da Universidade Estadual de Londrina. A revisão é bibliográfica de início e de levantamento, pois aplicou-se um questionário para a coleta de dados a duas populações distintas. Primeiro aos alunos que cursaram a disciplina de Mediação da Informação no ano de 2010 e segundo aos bibliotecários da mesma instituição.

Os campos empíricos que foram utilizados na pesquisa são a Biblioteca Central e o departamento de Ciência da Informação, ambos da Universidade Estadual de Londrina. Para coleta de dados da pesquisa utilizou-se como instrumento o questionário, devido às suas vantagens e relações com o objetivo da pesquisa. Depois de aplicado foi feito um confronto entre os pensamentos e as respostas obtidas nos questionários por essas duas populações e analisadas conforme os objetivos da pesquisa utilizando a análise de conteúdo. A técnica de análise de conteúdo durante sua aplicação visa descrever os dados/informações coletados de maneira objetiva, sistematizada e quantificada.

Laurence Bardin (2004, p. 33) define análise de conteúdo como "um conjunto de técnicas de análise das comunicações, que utiliza procedimentos sistemáticos e objetivos de descrição do conteúdo das mensagens", a autora defende que a análise de conteúdo fundamenta-se em codificar, categorizar um segmento do texto para entender o seu sentido.

Sabendo-se que a técnica utiliza procedimentos sistemáticos, é imprescindível que haja uma categorização dos dados, para que se possa aferir mais facilmente a denotação das informações.

O total de alunos que cursou a disciplina de Mediação da Informação no ano de 2010 foi de 18 e o total de bibliotecários de cargo e não de formação, na 
Biblioteca Central da UEL totaliza 23. O questionário foi composto por duas questões fechadas e cinco abertas.

\section{Resultados}

A mediação da informação, na perspectiva da maioria dos alunos e bibliotecários, ainda é entendida como ponte, ou seja, o profissional da informação que está em um ponto leva a informação para o usuário que se encontra em outro ponto. Pensamento um pouco distante do que a literatura científica afirma ser a mediação da informação, uma ação intencional de interferência e de participação ativa no processo de mediação. No entanto, 3 respondentes mencionaram o termo "interferência" ao discursar sobre o conceito de mediação da informação.

A maioria dos alunos e bibliotecários percebem a mediação da informação em todos os setores de uma biblioteca e/ou unidade de informação, ainda que 2 deles vislumbram a mediação da informação somente no setor de referência. A opinião da maior parte se aproxima do que a literatura diz a respeito, de acordo com ela a mediação está presente em todas as atividades do profissional da informação, seja de modo implícito ou explícito.

A maioria dos respondentes vislumbra a organização do conhecimento como classificação e agrupamento de materiais informacionais. Porém, 3 deles referiramse também à gestão como organização do conhecimento. Essas posições opõem-se ao que a literatura diz a respeito, uma vez que a organização do conhecimento lida com a construção de representações do conhecimento.

Para os alunos e bibliotecários em sua maioria, a organização do conhecimento é reconhecidamente importante devido à função que representa para a área e para as tantas atividades desempenhadas pelo profissional da informação.

Os respondentes destacaram que, para realizar a mediação da informação é preciso que a informação esteja organizada, ou seja, a mediação da informação vista como dependente da organização do conhecimento. Isso indica a não percepção deles da existência da mediação da informação além dos espaços de atendimento ao usuário, ou seja, não a percebem nas atividades meio desenvolvidas pelo profissional da informação, a medição implícita.

Ainda que existam muitas respostas divergentes, foi possível observar em alguns casos proximidade em relação ao entendimento por parte dos alunos e dos 
bibliotecários. É visível a aplicabilidade que os bibliotecários possuem em relação à mediação da informação e a organização do conhecimento em seu fazer diário, no entanto, no momento de descrever suas definições e relações, eles encontram um pouco de dificuldade. Já com os alunos, pode-se observar dificuldade em expressar o que representa a mediação da informação, lembrando que estes tiveram a disciplina no ano anterior ao da aplicação do questionário.

\section{CONSIDERAÇÕES FINAIS}

O principal foco deste artigo foi analisar a relação da mediação da informação no âmbito da organização do conhecimento, fundamentada nas abordagens teóricas da área. $O$ interesse em estudos de abordagem teórica se deu no momento em que os temas trabalhados ainda são pouco discutidos e lembrados, de maneira conjunta, no fazer bibliotecário, a respeito dos temas, analisados em conjunto, ainda é pequena. Foi realizado um levantamento de referências sobre os temas Mediação da Informação, Organização do Conhecimento e Organização da Informação, buscando suas definições, funções e relações. O corpus da análise foi constituído em sua maioria de publicações em eventos da área, de dissertações e teses defendidas em programas de pós-graduação com linhas de pesquisa relacionadas ao tema enfocado, artigos de periódicos científicos e dos artigos produzidos pelo grupo de pesquisa "Interfaces: Informação e Conhecimento", coordenado pelo Prof. Dr. Oswaldo Francisco de Almeida Júnior.

Os estudos realizados na pesquisa permitem afirmar que a mediação da informação, quando realizada de maneira consciente, é um dos principais meios de fazer com que o usuário se aproprie de forma satisfatória de uma informação. $O$ desenvolvimento dessa atividade deve ser contextualizado e socializado, para fazer sentido tanto aos bibliotecários como aos usuários. Realizando a mediação da informação, os bibliotecários criam melhores condições e ambientes de busca, recuperação, acesso e uso da informação. Assim, os usuários podem criar novos conhecimentos a partir de um conhecimento já existente.

As ações de organização do conhecimento e da informação estão diretamente relacionadas com a mediação da informação, uma vez que, como visto neste artigo, estão imbricadas. Independente da presença do usuário em bibliotecas a mediação da informação ocorre, cabe reforçar, também de maneira implícita. Mas 
a mediação da informação explícita exige a presença do usuário, a interação entre o profissional bibliotecário e o usuário neste caso é fundamental.

As informações obtidas nesta investigação revelaram que a mediação da informação acontece em todos os setores de uma biblioteca, porém de diferentes maneiras e com vários níveis de resultados. A relação entre setor de referência e mediação da informação ainda está presente no senso comum e no imaginário dos profissionais da área, pois foi a divisão mais lembrada pelos respondentes como espaço de mediação, todavia percebe-se que alguns também observam a mediação da informação em diferentes aspectos, como nos setores de aquisição, processamento técnico e até mesmo nas atividades de ação cultural, esta última pouco lembrada por parte dos profissionais.

Viu-se que o caráter da mediação e seu local de concretização não são fatores decisivos no momento em que se cogita a possibilidade de estabelecer uma ordem de importância e/ou relevância, pois cada mediação tem a sua importância dentro de um ambiente informacional. Muitos valorizam somente a mediação da informação explícita, que se dá nos serviços de referência e empréstimo, com a presença do usuário. Já outros participantes da pesquisa, conscientes da importância da mediação da informação como um todo, conseguem perceber e valorizar a mediação em todas as instâncias. Percebemos que os alunos e bibliotecários reconhecem a importância da organização do conhecimento, mas ainda restringem a sua relação com as atividades de classificação e catalogação. Não há um consenso a respeito do tema enfocado.

\section{REFERÊNCIAS}

ALMEIDA JÚNIOR, Oswaldo Francisco de. Mediação da informação e múltiplas linguagens. Tendências da Pesquisa Brasileira em Ciência da Informação, Brasília, v. 2, n. 1, p. 89-103, jan./dez. 2009. Disponível em: $<$ http://inseer.ibict.br/ancib/index.php/tpbci/article/view/17/39>. Acesso em: 05 fev. 2014.

Formação, formatação: profissionais da informação produzidos em série. In: VALENTIM, Marta (Org.). Formação do profissional da informação. São Paulo: Polis, 2002. p. 133-148. 
. Leitura, mediação e apropriação da informação. In: SANTOS, Jussara Pereira (Org.). A leitura como prática pedagógica na formação do profissional da informação. Rio de Janeiro: Fundação Biblioteca Nacional, 2007a. p. 33-45. . Mediação da Informação: ampliando o conceito de disseminação. In: ENCONTRO DE EDUCADORES E INVESTIGADORES EN BIBLIOTECOLOGIA, ARCHIVOLOGIA, CIENCIAS DE LA INFORMACIÓN Y DE LA DOCUMENTACIÓN DE IBEROAMÉRICA Y EL CARIBE (EDIBCIC), 7, 2006. Marília. Anais... Marília: UNESP, 2006. (CD-ROM).

- Mediação da Informação: discutindo a atuação do bibliotecário. In: FADEL, Bárbara (Org.). A informação nas organizações sociais: desafios em face de multiplicidade de enfoques. Marília: FUNDEPE, 2004a. (CD-ROM).

. Profissional bibliotecário: um pacto com o excludente. In: BAPTISTA, Sofia Galvão; MUELLER, Suzana Pinheiro Machado (Org.). Profissional da informação: 0 espaço de trabalho. Brasília: Thesaurus Editora, 2004b. p. 70-86.

BARDIN, Laurence. Análise de conteúdo. 3.ed. Lisboa: Edições 70, 2004.

BICHERI, Ana Lúcia Antunes de Oliveira. A mediação do bibliotecário na pesquisa escolar face a crescente virtualização da informação. 2008. 197f. Dissertação (Mestrado em Ciência da Informação) - Universidade Estadual Paulista - UNESP, Marília, 2008. Disponível em: <http://www.marilia.unesp.br/Home/PosGraduacao/Cienciadalnformacao/Dissertacoes/bicheri_alao_me_mar.pdf>. Acesso em: 05 fev. 2014.

BORTOLIN, Sueli. Mediação oral da literatura: a voz dos bibliotecários lendo ou narrando. 2010. 232f. Tese (Doutorado em Ciência da Informação) - Universidade Estadual Paulista - UNESP. Marília, 2010. Disponível em:

$<$ http://www.marilia.unesp.br/Home/Pos-

Graduacao/Cienciadalnformacao/Dissertacoes/bortolin_s_do_mar.pdf $>$. Acesso em: 05 fev. 2014.

BRÄSCHER, Marisa; CAFÉ, Lígia. Organização da Informação ou Organização do Conhecimento?. In: ENCONTRO NACIONAL DE PESQUISA EM CIÊNCIA DA INFORMAÇÃO, 9. 2008, São Paulo, Anais... São Paulo: ANCIB, 2008. Disponível em: <http://www.eca.usp.br/departam/cbd/enancib2008/cd/6\%20-

\%20Trabalhos\%20em\%20PDF/GT2/Oral/1835\%20-

\%20Organiza\%C3\%A7\%C3\%A30\%20da\%20Informa\%C3\%A7\%C3\%A30\%200u\%2 0Organiza\%C3\%A7\%C3\%A30\%20do\%20Conhecimento.pdf>. Acesso em: 05 fev. 2014.

BUFREM, Leilah Santiago; BREDA, Sônia Maria. Presença da lógica no domínio da organização do conhecimento: aspectos interdisciplinares no currículo do ensino superior. Perspectivas em Ciência da Informação, v. 16, n. 1, p. 185-194, jan./mar. 2011. Disponível em: <http://www.scielo.br/pdf/pci/v16n1/a11v16n1.pdf>. Acesso em: 05 fev. 2014. 
CERVANTES, Brígida Maria Nogueira. A construção de tesauros com a integração de procedimentos terminográficos. 2009. 209f. Tese (Doutorado em Ciência da Informação) - Faculdade de Filosofia e Ciências, Universidade Estadual Paulista, Marília, 2009. Disponível em: <http://www.marilia.unesp.br/Home/PosGraduacao/Cienciadalnformacao/Dissertacoes/cervantes_bmn_do_mar.pdf>. Acesso em: 05 fev. 2014.

DAVALLON, Jean. A mediação: a comunicação em processo?. Prisma.com, Porto, n. 4, 2007. Disponível em: <http://revistas.ua.pt/index.php/prismacom/article/viewFile/645/pdf>. Acesso em: 05 fev. 2014.

DIAS, Eduardo Wense. Biblioteconomia e ciência da informação: naturezas e relações. Perspectiva em Ciência da Informação, Belo Horizonte, v. 5, n. esp., p. 6780, jan./jun. 2000. Disponível em:

<http://portaldeperiodicos.eci.ufmg.br/index.php/pci/article/viewFile/556/338>. Acesso em: 05 fev. 2014.

GALVÃO, Maria Cristiane Barbosa. A organização da informação na perspectiva da ciência da informação e a dinâmica da cultura científica. In: HOFFMANN, Wanda Aparecida Machado; FURNIVAL, Ariadne Chloe Mary. (Org.). Olhar: ciência, tecnologia e sociedade. São Paulo: Pedro e João Ed.,CECH-UFSCar, 2008. p. 203223.

GOMES, Hagar Espanha; GUIMARÃES, Ludmila dos Santos. Organização do conhecimento e recuperação da informação na era das tecnologias. 2010.

Disponível em: <http://bibliotextos.files.wordpress.com/2012/03/organizac3a7c3a3odo-conhecimento-e-recuperac3a7c3a3o-da-informac3a7c3a3o-na-era-dastecnologias.pdf>. Acesso em: 05 fev. 2014.

LUFT, Celso Pedro. Minidicionário Luft. São Paulo: Ática, 2000.

NAVES, Madalena Martins Lopes. A importância de Ranganathan para a organização do conhecimento. In: NAVES, Madalena Martins Lopes; KURAMOTO, Hélio (Orgs.). Organização da informação: princípios e tendências. Brasília: Briquet de Lemos/Livros, 2006.

SANCHES, Gisele A. Ribeiro; RIO, Sinomar Ferreira do. Mediação da informação no fazer do bibliotecário e seu processo em bibliotecas universitárias no âmbito das ações culturais. InCID: R. Ci. Inf. e Doc., Ribeirão Preto, v. 1, n. 2, p. 103-121, jul./dez. 2010. Disponível em: <http://revistas.ffclrp.usp.br/incid/article/view/24/pdf>. Acesso em: 05 fev. 2014.

SOUZA, Francisco das Chagas de. Organização do conhecimento na sociedade. Florianópolis: Núcleo de Publicações, 1998. 
SOUZA, Rosali Fernandez de; SILVA, Roberta Pereira da. Organização e representação do conhecimento no contexto de gestão e avaliação: domínios interdisciplinares em ciência e tecnologia. In: ENCONTRO NACIONAL DE PESQUISA EM CIÊNCIA DA INFORMAÇÃO, 8. 2007, Salvador, Anais... Salvador: ANCIB, 2008. Disponível em: <http://www.enancib.ppgci.ufba.br/artigos/GT2-108.pdf>. Acesso em: 05 fev. 2014.

\section{Title}

Mediation Information and Knowledge Organization: interrelations

\section{Abstract}

Introduction: This article presents concepts and definitions of terms such as mediation of information and knowledge organization, from a theoretical framework.

Objective: To present the mediation process of information in the process of knowledge organization, under the perception of the students of Library Science and librarians, both of the Universidade Estadual de Londrina.

Methodology: A questionnaire was administered to the students and librarians to confront the literature with the data obtained, to conduct this questionnaire was applied the content analysis methodology.

Results: Additionally this article presents results as the way students and librarians perceive the issues discussed.

Conclusion: It is concluded that the mediation of information in addition to being an interference, it determines all the librarian's work; it's not yet clear to most respondents; and it's concluded that the actions of the knowledge organization also appear as mediation actions in the information professionals' daily work.

Key words: Mediation information. Interference. Knowledge Organization. Information Organization. University Library.

\section{Título}

Mediación de la Información y la Organización del Conocimiento: interrelaciones

\section{Resumen}

Introducción: En este artículo se presentan los conceptos y definiciones de mediación de la información y la organización del conocimiento, a partir de un marco teórico.

Objetivo: Presentar el proceso de mediación de la información en el proceso de organización del conocimiento en la percepción de los estudiantes de bibliotecología y los bibliotecarios.

Metodología: Se aplicó un cuestionario a los estudiantes y bibliotecarios, para hacer frente a la literatura con los datos obtenidos, se utilizó como metodología de análisis de contenido. 
Resultados: presentados como la forma en que los estudiantes y bibliotecarios perciben los temas tratados.

Concluisiones: Llegamos a la conclusión de que la mediación de la información, además de ser una interferencia, determina todos hacen el bibliotecario, esto todavía no está claro para la mayoría de los encuestados, y que las acciones de la organización del conocimiento también aparecen como acciones de mediación de la información en diarios profesionales.

Palabras clave: Mediación de la información. Interferencia; Organización del Conocimiento. Organización del la Información. Biblioteca de la Universidad.

Recebido em: 15.07.2014

Aceito em: 05.10.2014 